\title{
Pengaruh Model Latihan Passing Terhadap Kemampuan Passing Bawah Dan Passing Atas Pemain Bolavoli
}

\author{
Rahmat Baitul Afdi ${ }^{1}$, Zulman $^{2}$, Ali Asmi ${ }^{3}$ \\ ${ }^{123}$ Fakultas Ilmu Keolahragaan, Universitas Negeri Padang, Indonesia. \\ E-mail: rahmadbai@yahoo.com ${ }^{1}$, zulman@fik.unp.ac.id ${ }^{2}$ aliasmi@fik.unp.ac.id
}

\begin{abstract}
Abstrak
Masalah dalam penelitian ini yaitu rendahnya kemampuan untuk lulus dan melewati Negara pemain voli SMP JUNIOR 2 Kecamatan Akabiluru Kabupaten Lima puluh kota. Penelitian ini bertujuan untuk mengetahui pengaruh model praktik passing terhadap kemampuan passing bawah dan passing atas pemain bola voli SMP Negeri 2 Kecamatan Akabiluru Kabupaten Lima puluh kota.

Jenis penelitian ini adalah eksperimen semu. Populasi dalam penelitian ini yaitu, pemain bola voli mengikutilatihan sebanyak 20 orang, dengan rincian putra dan putri pemain 14 orang 6 orang. Teknik pengambilan sampel menggunakan purposive sampling. Dengan demikian jumlah sampel yang diambil sebanyak 14 orang putra atlet saja. Data dikumpulkan dengan menggunakan pengukuran terhadap kemampuan passing bawah dan lewat. Data dianalisis menggunakan uji-t untuk sampel dependen.

Hasil penelitian menunjukkan bahwa: 1) terdapat model pengaruh latihan secara signifikan terhadap kemampuan passing pemain voli SMP Negeri 2 Kecamatan Akabiluru Lima Puluh Kecamatan kota, dengan hasil analisis thitung $=$ ttabel $>9.09=2,16$, dan diterima secara empiris, serta peningkatan kemampuan passing bawah pemain bola voli 3,64 dari nilai rata-rata untuk menghitung tes awal dan tes akhir 8,93 menjadi12,57. 2) terdapat pengaruh model latihan secara signifikan terhadap kemampuan passing pemain voli papan atas di SMP Negeri 2 Kecamatan Akabiluru Kelima kabupaten kota, dengan hasil analisis thitung $=$ ttabel $>16,97=2.16$, dan diterima secara empiris, serta terjadi peningkatan 3,43 yaitu dari nilai rata-rata untuk menghitung tes awal dan tes terlambat menjadi $8,2111,64$.
\end{abstract}

Kata Kunci: Latihan Passing Model Bola Voli

\section{Abstract}

The problem in this study i.e. the low capability of passing down and passing over the State JUNIOR HIGH SCHOOL volleyball player 2 Kecamatan Akabiluru District Fifty cities. This research aims to know the influence of model practice passing against the ability of passing down and passing over the State JUNIOR HIGH SCHOOL volleyball player 2 Kecamatan Akabiluru District Fifty cities.

This type of research is quasi experiment. The population in this study i.e., a volleyball player mengikutilatihan as many as 20 people, with details of the player's son and daughter 14 persons 6 persons. Sampling techniques using a purposive sampling. Thus the number of samples taken as many as 14 people athlete son only. The data collected by using measurement against the ability of passing down and passing over. The data were analyzed using t-test for dependent samples.

The results showed that: 1) there is a model of the influence of exercise significantly to the passing ability of passing down volleyball player SMP Negeri 2 Kecamatan Akabiluru Fifty District of 
Sport Science: Jurnal Sain Olahraga dan Pendidikan Jasmani ISSN 114-562X (Cetak), ISSN XXXX-XXXX(Online)

http://sportscience.ppj.unp.ac.id/index.php/jss/index

the city, with the results of the analysis of thitung $=$ ttabel $>9.09=2.16$, and accepted empirically, as well as an increase in the capability of passing down volleyball players of 3.64 from average value to calculate the initial test and the final test 8.93 menjadi12,57. 2) there is the influence of model of exercise significantly to the passing ability of passing the top volleyball players in junior high Country 2 Kecamatan Akabiluru Fifty District of the city, with the results of the analysis of thitung = ttabel > $16.97=2.16$, and accepted in empirical, as well as going on an increase of 3.43 i.e. from the average value to calculate the initial tests and tests late became 8.21 11.64.

\section{Keywords: Model Volleyball Passing Drills}

\section{PENDAHULUAN}

Permainan bolavoli merupakan olahraga yang sudah populer di masyarakat, baik di indonesia maupun di dunia. Tujuan dari pembinaan dan pengembangan olahraga bolavoli di Indonesia adalah untuk meningkatkan prestasi, maka untuk dapat mengejar prestasi puncak hendaknya ditempuh melalui pendekatan secara ilmiah seperti yang dijelaskan dalam UU RI No.3 pasal 20 ayat 5 (2005) bahwa :

"Untuk kemajuan olahraga prestasi, pemerintah daerah dan atau masyarakat dapat mengembangkan: a) Perkumpulan olahraga. b) Pusat penelitian dan pengembangan ilmu pengetahuan dan teknologi keolahragaan. c) Sentra pembinaan olahraga prestasi. d) Pendidikan dan pelatihan tenaga keolahragaan. e) Prasarana dan sarana olahraga prestasi. f) Sistem pemanduan dan pengembangan bakat olahraga. g) Sistem Informasi keolahragaan ;dan h) Melakukan uji coba kemampuan prestasi olahragawan pada tingkat daerah, nasional dan Internasional sesuai dengan kebutuhan".

Untuk mencapai prestasi yang optimal diperlukan suatu latihan yang terprogram dengan baik. Latihan juga membentuk atau mengubah respon fisiologis, di samping elemen fisik yang terlibat dalam latihan untuk menjadi seorang pemain yang handal. Pada saat ini banyak hal yang perlu diperhatikan oleh pembina atau pelatih dan oleh atlet itu sendiri, misalnya faktor teknik, taktik, mental dan kondisi fisik dan juga model latihan yang mendukung peningkatan faktor - faktor di atas.

Di Indonesia olahraga bolavoli dikelola oleh induk organisasi pengurus besar persatuan bolavoli seluruh Indonesia (PB.PBVSI). PB.PBVSI terus berupaya meningkatkan prestasi bolavoli dengan mengadakan berbagai kompetisi secara bertahap dan berjenjang seperti Pekan Olahraga Provinsi (PORPROV), Pekan Olahraga Nasional (PON) bahkan Internasional.

Namun sangatlah mengecewakan PBVSI Sumatera Barat tidak banyak memiliki pemain bolavoli yang diandalkan. Hal ini terbukti dari hasil PON, Tim bolavoli Sumbar belum pernah mendapatkan prestasi terbaik di PON. Artinya PBVSI Sumatera Barat belum berhasil memperoleh prestasi maksimal. Mungkin banyak faktor yang menyebabkan kegagalan dalam mencapai prestasi yang membanggakan. Faktor- faktor tersebut adalah kondisi fisik, teknik, taktik, dan mental. Semua faktor tersebut sangatlah diperlukan dalam permainan bolavoli. Salah satu faktor yang penting adalah program latihan teknik yang diterapkan kurang baik. Perolehan angka dalam permainan bolavoli diperoleh dari hasil kerjasama pemain dalam mematikan bola di di daerah lawan dan tim yang melakukan gerakan passing atas, passing bawah, smash dan block merupakan pondasi atau dasar bagi seorang untuk dapat bermain bolavoli dengan baik.

Dari sekian banyak teknik bolavoli yang dilatih yang penting adalah passing, passing bawah yang merupakan awal terjadinya penyusunan strategi penyerangan untuk memperoleh angka penuh dalam permainan bolavoli. Semakin bagus passing bawah yang dimiliki oleh setiap pemain maka semakin baik penyusunan serangan yang dilancarkan sehingga lebih mudah untuk memperoleh angka. 
Berdasarkan uraian di atas dapat dikemukakan passing bawah mempunyai fungsi penting dalam permainan bolavoli. Untuk dapat menghasilkan kemampuan passing bawah yang baik dibutuhkan suatu program latihan yang sistematis. SMP Negeri 2 merupakan salah satu tempat pembinaan olah raga bolavoli yang cukup representatif di Kecamatan Akabiluru, Lima Puluh Kota. SMP Negeri 2 Kecamatan Akabiluru bertempat di jalan pendidikan suayan km 10 Suayan Kecamatan Akabiluru, Kabupaten Lima Puluh Kota memiliki lapangan yang cukup bagus serta pelatih yang cukup berpengalaman. Namun sangat disayangkan prestasi yang dihasilkan belum memuaskan meskipun sudah melakukan pembinaan dari usia tingkat SMP.

Untuk mempelajari teknik-teknik dasar bermain bolavoli yang baik, sangat dibutuhkan sekali oleh pemain teknik -teknik penguasaan bola dalam passing bawah. Passing bawah adalah suatu teknik dasar keterampilan mempassing bola ke daerah lawan atau teman sendiri yang ditujukan agar pemain mempunyai kemampuan untuk mengenali, menguasai dan memainkan bola agar teknik dasar lain dapat dilakukan dengan baik.

Setelah seorang pemain dapat merasakan dan bisa memahami olahraga tersebut dengan keahlian penguasaan bola. Juga dibutuhkan penguasaan teknik bermain bolavoli yang baik,karena kemampuan teknik bermain sangat mendukung seseorang pemain dalam meningkatkan keterampilan. Di antara keterampilan dalam permainan bolavoli, hal yang penting dalam mengembangkan seorang pemain bolavoli ialah kemampuan passing. Ini merupakan keterampilan dasar bermain bolavoli yang harus dikembangkan dan dimiliki oleh pemain serta diberikan dalam setiap situasi latihan.Dalam usaha meningkatkan kemampuan passing bawah atlet bolavoli SMP Negeri 2 Kecamatan Akabiluru, Lima Puluh Kota.

Menurut pengamatan penulis di lapangan, olahraga bolavoli merupakan salah satu cabang olahraga yang sangat disenangi oleh siswa. Sebab olahraga ini merupakan olahraga yang sering membawa nama baik sekolah, baik di tingkat kecamatan maupun Kabupaten lima Puluh Kota. Kegiatan olahraga bolavoli sudah berjalan dengan baik namun masih banyak juga kendala yang sering terjadi pada pemain pada saat melakukan pertandingan dan diperkuat lagi dari keterangan Wendra Rahmat selaku pelatih team bolavoli SMP N 2 Kecamatan Akabiluru Lima Puluh Kota mengatakan kemampuan passing bawah dan passing atas pemain bolavoli SMP N 2 Kecamatan Akabiluru Lima Puluh Kota ini masih rendah, hal ini dilihat pada saat pertandingan uji coba passing bawah dan passing atas pemain selalu tidak tepat sasaran, dan kurang akurat dalam menerima bola servis dari lawan yang menyebabkan bola melenceng jauh dari pengumpan, sehingga menyebabkan tim sulit dalam membangun sebuah serangan dan sulit mematikan bola di petak lawan.

Dengan demikian maka dapat dikatakan dengan jelas bahwa kemampuan passing bawah dan passing atas pemain Bolavoli SMP N 2 Kecamatan Akabiluru, Kabupaten Lima Puluh Kota ini masih rendah dan pengamatan penulis menduga salah satu faktor yang menyebabkan rendahnya kemampuan passing bawah dan passing atas dari tim ini adalah bentuk latihan yang kurang tepat sehingga tim ini mengalami kendala untuk dapat berprestasi.

Berdasarkan pemaparan di atas jelaslah bahwa yang menjadi masalah adalah rendahnya kemampuan teknik passing bawah dan passing atas pemain bolavoli SMP Negeri 2 Kecamatan Akabiluru, Kabupaten Lima Puluh Kota yang disebabkan banyak faktor. Diantaranya model yang diberikan pelatih terhadap pemain. Maka peneliti tertarik untuk melakukan penelitian mengenai Pengaruh Model Latihan Passing dalam latihan teknik dasar khususnya passing bawah dan passing atas bolavoli terhadap kemampuan passing bawah dan passing atas siswa SMP Negeri 2 kecamatan Akabiluru, Kabupaten Lima Puluh Kota yang mengikuti ekstrakurikuler pengembangan diri bolavoli.

\section{METODE}

Penelitian ini merupakan jenis penelitian eksperimen semu (quasi experimental). Tujuannya adalah untuk memperoleh informasi yang merupakan perkiraan bagi informasi yang dapat diperoleh dengan eksperimen yang sebenarnya dalam keadaan yang tidak memungkinkan untuk mengontrol 
dan memanipulasi semua variabel yang relevan, pengontrolan variabel hanya dilakukan terhadap satu variabel saja yaitu variabel yang dianggap paling dominan (Sukmadinata, 2005:59). Penelitian ini bermaksud untuk mencari pengaruh model latihan passing terhadap kemampuan passing bawah dan passing atas pemain voli SMP N 2 Kecamatan Akabiluru, Kabupaten Lima Puluh Kota.

Penelitian ini dilakukan di lapangan Bola Voli SMP N 2 Kecamatan Akabiluru, kabupaten Lima Puluh Kota. Penelitian ini dilaksanakan setelah diseminarkan.

\section{HASIL DAN PEMBAHASAN \\ Hasil Penelitian}

Berdasarkan hasil penelitian sesuai dengan hipotesis yang diajukan, maka model latihan passing memberikan pengaruh yang signifikan terhadap kemampuan passing bawah di SMP Negeri 2 Kecamatan Akabiluru Kabupaten Lima Puluh Kota, dan diterima kebenarannya secara empiris denganperolehan $t_{\text {hitung }}=9,09>t_{\text {tabel }}=2,16$. Selanjutnya diketahui bahwa kemampuan passing bawah dari 14 orang pemain bolavoli setelah diberikan perlakuan dengan menggunakan model latihan passing terjadi peningkatan sebesar 3,64. Hal ini dapat diketahui dari nilai rata-rata (mean) pada tes awal yaitu 8,93, dan menjadi 12,57 pada tes akhir.

Passing dalam permainan bolavoli merupakan suatu teknik dalam permainan bolavoli yang tujuannya adalah untuk mengoper bola kesuatu tempat atau kepada teman sendiri dalam satu regu, untuk selanjutnya dimainkan kembali dan dapat juga dikatakan sebagai langkah awal untuk menyusun serangan kepada regu lawan. Menurut Erianti (2004: 159) "passing bawah merupakan elemen utama untuk mempertahankan regu dari serangan lawan (bola yang datangnya terlalu keras dan sulit dimainkan dengan passing atas, maka diamnil dengan passing bawah).

Berpedoman pada pendapat di atas, maka jelaslah bahwa passing bawah merupakan salah satu teknik penting yang harus dikuasai oleh pemain bolavoli, terutama dalam mempertahankan regu dari serangan lawan. Misalnya saja seorang pemain libero harus memiliki teknik passing bawah dengan baik, karena pemain lebero fungsi sebagai pemain bertahan. Libero harus mampu menerima bola-bola tajam dari pukulan smash, servis atas atau lompat yang merupakan serangan utama dari tim lawan.

Di samping untuk merpertahankan serangan dari tim lawan, dan juga sangat berperan untuk membangun serangan. Passing bawah dapat berfungsi sama dengan passing atas seperti memberikan umpan di atas net oleh tosser atau pemain yang lain yang berada dekat net. Dalam permainan passing bawah dapat dilakukan dengan satu atau dua tangan yang penggunaannya sesuai situasi dan tujuan yang hendak di capai. Untuk dapat memiliki kemampuan passing bawah dengan baik tentu diperlukan latihan secara kontinyu, dan proses latihan tersebut dilakukan secara yang sistematis, dan berulangulang dengan teknik atau cara yang benar.

Dalam penelitian ini salah satu upaya yang dilakukan dapat meningkatkan kemampuan passing bawah pemain bolavoli di SMP Negeri 2 Kecamatan Akabiluru Kabupaten Lima Puluh Kota, adalah dengan memberikan model-model latihan passing selama 16 minggu, dan terlebih dahulu 
dilakukan tes awal dan setelah perlauan kemudian dilakukan tes akhir, dan hasilnya memang terjadi peningkatan secara signifikan. Model-model latihan passing yang diberikan antara lain adalah passing bawah dengan bola rendah berpasangan, passing bawah ke dinding sasaran dan bergerak ke samping kiri ataupun bergerak ke samping kanan, passing bawah bergerak maju dan mundur, passing bawah bergerak ke belakang, dan lain-lain sebagainya.

Perlu juga diketahui dan dipahami oleh pemain bolavoli bahwa untuk memiliki passing bawah dengan baik, pemain harus mampu melakukan latihan passing bawah dengan teknik atau cara yang benar dalam pelaksanaannya. Cara pelaksanaan passing bawah menurut Syafruddin (2004:70) adalah: "Sikap lengan betul-betul diluruskan dan dirapatkan. Satu tangan menempel pada tangan yang lain sehingga ibu jari sejajar. Perkenaan bola antara pergelangan tangan dan siku, tepatnya perkenaan bola sedikit diatas pergelangan tangan. Jalan gerakan bola di passing dengan meluluruskan dan ayunan kedua lengan. Titik berat tubuh berada pada kaki yang didepan kedua lengan tidak begitu aktif. Bahu sedikit terangkat, bola seolah-olah ditekan kearah yang diinginkan. Lengan diayun sampai datar dan tubuh berada dibawah bola, bahu harus menunjuk ke bola yang diinginkan".

Selanjutnya untuk memiliki kemampuan passing bawah dengan baik, pemain bolavoli harus mempersiapkan dengan baik kemampuan beberapa unsure kondisi fisik yang dominan dibutuhkan dalam pelaksanaan teknik passing bawah. Diantaranya adalah kemampuan daya tahan kekuatan otot lengan, kelincahan yaitu kemampuan pemain dalam merubah-rubah posisi tubuh atau bagian-bagian tubuh dengan cepat dan tepat tanpa kehilangan keseimbangan. Kemudian kelentukan yaitu kemampuan menggerakan tubuh atau bagian-bagiannya seluas mungkin tanpa terjadi ketegangan sendi dan cidera otot, semua unsur kondisi fisik ini tentu dilakukan sebelum diberikan model-model latihan teknik passing diberikan.

Hasil penelitian kedua sesuai dengan hipotesis yang diajukan, maka model latihan passing memberikan pengaruh yang signifikan terhadap kemampuan passing atas bolavoli pemaindi SMP Negeri 2 Kecamatan Akabiluru Kabupaten Lima Puluh Kota, dan diterima kebenarannya secara empiris denganperolehan $t_{\text {hitung }}=16,97>t_{\text {tabel }}=2,16$. Selanjutnya diketahui bahwa kemampuan passing atas bolavoli dari 14 orang pemain setelah diberikan perlakuan dengan menggunakan model latihan passing terjadi peningkatan sebesar 3,43. Hal ini dapat diketahui dari nilai rata-rata (mean) pada tes awal yaitu 8,21, dan menjadi11,64 pada tes akhir.

Sesuai dengan temuan dalam penelitian ini yang telah dikemukakan di atas, maka jelaslah bahwa dengan memberikan model-model latihan passing dapat memberikan pengaruh yang signifikan terhadap kemampuan passing atas pemain bolavoli SMP Negeri 2 Kecamatan Akabiluru Kabupaten Lima Puluh Kota. Kemudian dapat juga diartikan bahwa dengan memberikan model-model latinan passing dapat meningkatkan kemampuan passing atas pemain bolavoli tersebut. Passing atas merupakan elemen terpenting dalam permainan bolavoli, tanpa teknik ini tidak mungkin dapat dilakukan suatu serangan yang berarti.

Menurut Bachtiar (1999:45) passing atas dalam permainan bolavoli merupakan teknik memainkan bola yang dilakukan seorang pemain. Passing atas juga disebut dengan umpanan, umpanan yang dimaksud adalah sajian yang diberikan kepada teman seregu untuk dipukul 
dengan melakukan serangan kepetak lawan. Passing atas juga merupakan langkah awal untuk menyusun pola serangan, dan jika ditinjau dari keuntungan, maka teknik passing atas akan lebih menguntungkan dibanding dengan passing bawah karena mengunpan dengan teknik passing atas lebih menjamin ketepatan sasarannya dari pada passing bawah. Kemudian umpan yang baik harus memenuhi kebutuhan sesuai dengan tujuan, seperti memberi umpan pada smash untuk smash normal, semi dan umpan dorong, serta lain-lainnya.

Memang tidak mudah bagi pemain untuk memiliki teknik passing atas dengan baik, pemain harus mengerti dan paham bagaimana cara pelaksanaan passing atas dengan baik dan benar. Misalnya saja sikap permulaan yaitu kedua kaki di buka selebar bahu, berat badan menumpuk pada tapak kaki bagian depan, lutut ditekuk, tempatkan badan secepat mungkin di bawah bola dengan kedua tangan diangkat lebih tinggi dari jari-jari tangan terbuka lebar membentuk cekungan seperti setengah lingkaran bola.

Gerakan pelaksanaanya adalah pada saat bola berada di atas dan sedikit didepan dahi, lengan diluruskan dengan gerak agak eksplosif untuk mendorong bola. Perkenaan bola pada permukaan jari-jari yaitu ruas pertama dan kedua serta dominan mendorong bola adalah ibu jari, jari telunjuk dan jari tengah. Jari-jari agak ditegangkan pada waktu bersentuhan dengan bola, kemudian diikuti dengan gerakan pergelangan tangan agar bola dapat memantul dengan baik.

Terakhir dilanjutkan dengan meluruskan lengan ke depan atas sebagai suatu gerakan lanjutan, diikuti dengan memindakan berat badan ke depan dengan melangkahkan kaki belakang ke depan dan segera mengambil sikap dalam posisi normal kembali. Dalam pelaksanaan passing atas dalam permainan bolavoli, tentu didukung oleh beberapa unsur kondisi fisik yang dominan dibutuhkan.

Diantaranya adalah kekuatan otot jari-jari tangan yaitu kemampuan otot-otot jari tangan mengatasi beban, tanpa kekuatan jari-jari tangan tidak akan mampu mendorong bola. Kemudian koordinasi mata-tangan atau kemampuan integrasi antara mata sebagai pemegang utama dan tangan sebagai pemegang fungsi yang melakukan gerakan tertentu, dalam hal ini kedua mata akan memberitahu kapan bola berada di suatu titik agar tangan langsung melakukan pukulan yang tepat. Selanjutnya daya tahan kekuatan otot lengan, dan kelentukan pergelangan, serta lain-lain sebagainya. Semua unsur kondisi fisik yang dominan dibutuhkan melakukan passing atas harus dilatih secara kontinyu dan dengan cara yang benar.

\section{KESIMPULAN}

Terdapat pengaruh model latihan passing secara signifikan terhadap kemampuan passing bawah bolavoli pemaindi SMP Negeri 2 Kecamatan Akabiluru Kabupaten Lima Puluh Kota, dengan hasil analisis $t_{\text {hitung }}=9,09>t_{\text {tabel }}=2,16$, dan diterima kebenarannya secara empiris, serta adanya peningkatan kemampuan passing bawah bolavolipemain ini sebesar 3,64 yaitu dari nilai rata-rata hitung tes awal8,93 dan tes akhir menjadi12,57. 
Terdapat pengaruh model latihan passingsecara signifikanterhadap kemampuan passing atas bolavoli pemain di SMP Negeri 2 Kecamatan Akabiluru Kabupaten Lima Puluh Kota, dengan hasil analisis $t_{\text {hitung }}=16,97>t_{\text {tabel }}=2,16$, dan diterimakebenarannya secara empiris, serta terjadi peningkata sebesar 3,43 yaitu dari nilai rata-rata hitung tes awal8,21 dan tes akhir menjadi1 1,64.

Guru penjasorkes sebagai pelatih bolavoli di SMP Negeri 2 Kecamatan Akabiluru Kabupaten Lima Puluh Kota agar menggunakan model-model latihan passing, kemampuan passing dapat ditingkatkan. Pemain bolavoli di SMP Negeri 2 Kecamatan Akabiluru Kabupaten Lima Puluh Kota, agar disiplin dan rajin mengikuti model-model latihan passing sesuai dengan arahan dan petujuk dari pelatih.

Kepala sekolah, agar memberikan dukungan dan perhatian terhadap pemain bolavoli di sekolah yang dia pimpin dengan memberikan kesempatan pada pemain untuk mengikuti pertandinganpertandingan yang sudah diagendakan oleh Dinas Pendidikan atau pertandingan lainnya, sehingga kemampuan teknik bolavoli dapat ditingkatkan.

\section{DAFTAR RUJUKAN}

Ahmadi, Nuril. 2007.Panduan Olahraga Bola Voli.Solo: Era Pustaka Utama

Arsil.2015.Evaluasi Pendidikan Jasmani dan Olahraga.Padang:FIK Universitas Negeri Padang.

Bachtiar.1999.Dasar-dasar Kepelatiahan. Padang : DIP Proyek Universitas Negeri Padang.

Erianti. 2004. Bola Voli. (Bahan Ajar). Padang. FIK UNP

Khamim.2013. "Pengaruh Latihan Passing Bawah Menggunakan Tembok Sasaran Dengan memakai Lingkaran dan Tali Terhadap Kemampuan Passing Bawah Pada Permainan Bolavoli Klub Idola Plajan Kabupaten Jepara Tahun 2013".Disertasi tidak Diterbitkan.UNS

Kurniawan.2011. Buku Pintar Olahraga. Jakarta: Laskar Aksara.

Rosmawati. Test Pengukuran dan Evaluasi Dalam Pendidikan Jasmani Kesehatan dan Rekreasi. FIK. UNP. Padang.

Sugiyono. 2014. Memahami Penelitian Kualitatif. Bandung : CV. Alfabeta

Sukmadinata, Nana Syaodih. 2009. Metode Penelitian Pendidikan. Bandung: PT. Remaja Rosda Karya.

Suwirman. 2007. Dasar-Dasar Penelitian. FIK. UNP. Padang.

Syafruddin.1999.Pengetahuan Dasar Permainan Bolavoli. Padang: DIP Proyek Universitas Negeri Padang.

Syafruddin.2004. Permainan Bolavoli.Padang: UNP Press Padang. 


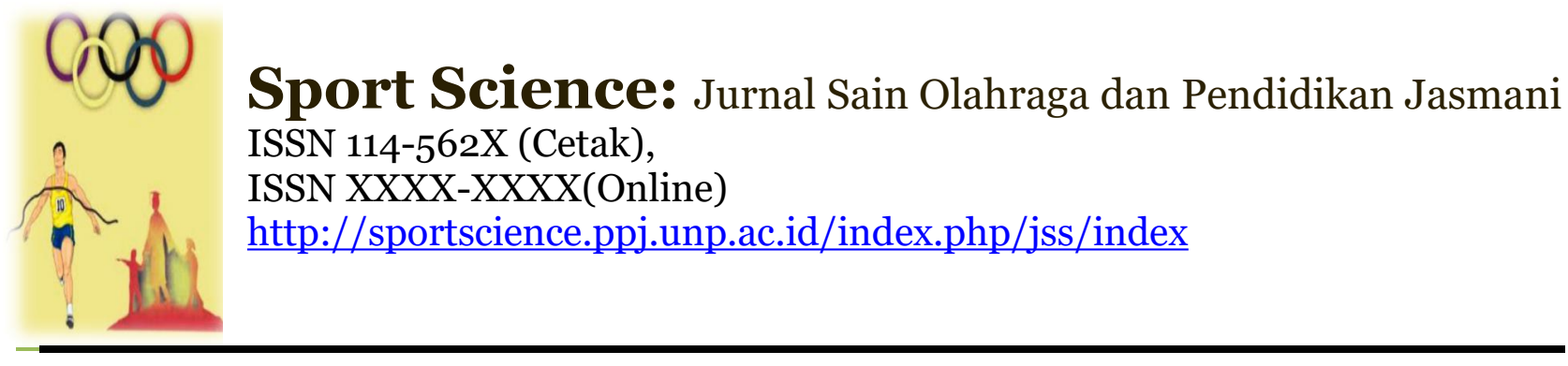

Undang - Undang RI No: 03 pasal 20 ayat 5 (2005). Tentang Sistem Keolahragaan Nasional.

Yunus, M. 1992. Olahraga Pilihan Bolavoli. Jakarta Departemen Pendidikan Direktorat Jendral Pendidikan Tinggi Proyek Pembinaan Tenaga Kependidikan. 